\section{High Molecular Mass Polyethylene Aqueous Latexes by Catalytic Polymerization**}

\section{Florian M. Bauers and Stefan Mecking*}

Emulsion polymerization of olefinic monomers is one of the most important and also versatile polymerization processes. ${ }^{[1]}$ Polymer latexes are obtained, that is, stable aqueous dispersions of surfactant-stabilized polymer microparticles in the range of 50 to $1000 \mathrm{~nm}$ diameter. Numerous applications of latexes (for example, in coatings) involve the formation of films upon evaporation of the dispersing medium, and the

[*] Dr. S. Mecking, Dipl.-Chem. F. M. Bauers

Institut für Makromolekulare Chemie und Freiburger Materialforschungszentrum der Albert-Ludwigs-Universität Freiburg

Stefan-Meier-Strasse 31, 79104 Freiburg (Germany)

Fax: $(+49) 761-203-6319$

E-mail: mecking@uni-freiburg.de

[**] This work was supported by BASF AG. F.M.B. thanks the Deutsche Forschungsgemeinschaft for a stipend (Graduiertenkolleg Strukturbildung in makromolekularen Systemen). We thank R. Thomann for TEM analyses, and U. Westphal for skillful assistance with GPC investigations. environmental friendliness and nonflammability of water is particularly advantageous. To date, polymer latexes are produced by free-radical processes exclusively. ${ }^{[2]}$ Transition metal catalyzed coordination polymerization has received comparatively little attention, as the early transition metal catalysts $^{[3]}$ used commercially for polyolefin production are extremely sensitive to moisture. Carrying out such reactions in water is a highly attractive goal, however, as many polymer microstructures are not available by means other than catalytic polymerization. $\mathrm{We}^{[4]}$ and others ${ }^{[5]}$ have recently reported the successful polymerization of ethylene in water by neutral nickel(II) complexes. ${ }^{[6,7]}$ However, dispersions consisting of low molecular mass material with a degree of polymerization of less than $100\left(M_{\mathrm{n}}\right.$ values typically $\left.1000 \mathrm{~g} \mathrm{~mol}^{-1}\right)$ were obtained. The formation of higher molecular mass polymers (with chain length considerably above the entanglement limit) is a crucial prerequisite to fully exploit the unique property profile of latexes. At the same time, the complex steps of microparticle formation during polymerization must afford stable dispersions of these high molecular mass polymers.

With complexes $\left[\left(\mathrm{X}^{\frown} \mathrm{O}\right) \mathrm{Ni}^{\mathrm{II}} \mathrm{R}(\mathrm{L})\right]$, where $\mathrm{X}=\mathrm{P}$ (type $\mathbf{1}$ ) or $\mathrm{X}=\mathrm{N}$ (type $2, \mathrm{~N} \frown \mathrm{O}=$ salicylaldimine), materials of relatively similar maximum weight-average molecular mass $\left(M_{\mathrm{w}}\right)$ are accessible by traditional ethylene polymerization in apolar organic media. ${ }^{[8,9]}$ By contrast, in water, the latter offer access to polymers with much higher $M_{\mathrm{w}}$ and $M_{\mathrm{n}}$ values than the low molecular weight materials obtained in water with complexes of type $1 .^{[4 b]}$ In regard to particle formation, a comparison with free-radical emulsion polymerization is instructive. ${ }^{[10]}$ In classical emulsion polymerization, water-soluble initiators are used. Chain growth initially affords water-soluble oligomeric radicals, which nucleate particles by collapsing upon themselves after reaching a certain chain length or by entering a surfactant micelle. Similar considerations appear reasonable for the aforementioned emulsion-type catalytic polymerization by a hydrophilically modified water-soluble complex of type 1, which affords stable latexes of low molecular mass material. ${ }^{[4]}$ However, a certain water-sensitivity ${ }^{[4 b, 9 c]}$ of salicylaldimine-substituted complexes (type 2) can be problematic to an analogous approach.

As a different concept to enable formation of a large number of latex particles during polymerization, a very fine dispersion of the catalyst precursor was achieved in the form of a solution of a lipophilic complex (2a) in submicron-size compartments of a hydrocarbon solvent, dispersed in the continuous aqueous phase. ${ }^{[14]}$ A mixture of water, surfactant, and a solution of the complex in a small amount of hydrocarbon (toluene and a small portion of hexadecane as a hydrophobic additive $\left.{ }^{[11]}\right)$ was subjected to high shear, generated

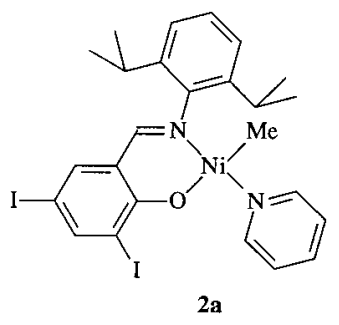
either by ultrasound or by means of a modified high-pressure homogenizer. Mini-emulsions consisting of a large number of small hydrophobic droplets (diameter about $100 \mathrm{~nm}, 10^{16}$ $10^{17}$ droplets $\mathrm{L}^{-1}$ ) containing the catalyst resulted. Exposure of the mini-emulsions to ethylene in a pressure reactor resulted in polymerization to form stable polyethylene latexes 
Table 1. Polymerization conditions ${ }^{[a]}$ and results.

\begin{tabular}{|c|c|c|c|c|c|c|c|c|c|c|c|}
\hline Entry & $\begin{array}{l}n \text { (cat.) } \\
{[\mu \mathrm{mol}]}\end{array}$ & $\begin{array}{l}\text { Toluene } \\
\text { [vol\%] }\end{array}$ & $\begin{array}{l}\mathrm{C}_{16} \mathrm{H}_{34} \\
{[\mathrm{vol} \%]}\end{array}$ & type $^{[\mathrm{b}]}$ & $\begin{array}{l}\text { Surfactant } \\
\qquad c\left[\mathrm{mmol} \mathrm{L}^{-1}\right]\end{array}$ & $\begin{array}{l}\text { Emulsification } \\
\operatorname{method}^{[c]}\end{array}$ & $\mathrm{TON}^{[\mathrm{d}]}$ & $\begin{array}{l}M_{\mathrm{n}} \\
{\left[\mathrm{g} \mathrm{mol}^{-1}\right]}\end{array}$ & $\begin{array}{l}M_{\mathrm{w}} \\
{\left[\mathrm{g} \mathrm{mol}^{-1}\right]}\end{array}$ & $M_{\mathrm{w}} / M_{\mathrm{n}}$ & $\begin{array}{l}\bar{d}^{\text {[e] }} \\
{[\mathrm{nm}]}\end{array}$ \\
\hline 1 & 25 & 1 & 2 & SDS & 17 & US & 2515 & $1.4 \times 10^{5}$ & $3.2 \times 10^{5}$ & 2.3 & 330 \\
\hline 2 & 23 & 1 & 0.3 & SDS & 35 & US & 1206 & $1.2 \times 10^{5}$ & $3.3 \times 10^{5}$ & 2.7 & 220 \\
\hline 3 & 36 & 1 & 0.3 & SDS & 17 & US & 1135 & $8.5 \times 10^{4}$ & $2.6 \times 10^{5}$ & 3.1 & 260 \\
\hline 4 & 29 & 1 & 0.3 & SDS & 5 & US & 1230 & $1.0 \times 10^{5}$ & $4.5 \times 10^{5}$ & 4.5 & $(485)^{[f]}$ \\
\hline 5 & 36 & 1 & 0.3 & Trit & 11 & US & 959 & $8.9 \times 10^{4}$ & $1.9 \times 10^{5}$ & 2.1 & 100 \\
\hline 6 & 32 & 1 & 0.3 & K30 & 18 & US & 990 & $9.0 \times 10^{4}$ & $2.5 \times 10^{5}$ & 2.8 & 240 \\
\hline 8 & 32 & 1 & 0.3 & SDS & 17 & HP & 75 & $2.0 \times 10^{4}$ & $3.4 \times 10^{4}$ & 1.7 & 90 \\
\hline 9 & 44 & 4 & 1 & Lut & 5 & HP & 265 & $1.6 \times 10^{4}$ & $2.4 \times 10^{4}$ & 1.5 & 250 \\
\hline
\end{tabular}

[a] $30^{\circ} \mathrm{C}, 45$ bar constant ethylene pressure, $2 \mathrm{~h}$ reaction time. Total volume of water and organic solvents: $100 \mathrm{~mL}$. [b] SDS $=$ sodium dodecylsulfate, Lut $=$ Lutensol AT $80\left(\mathrm{C}_{16}-\mathrm{C}_{18}\right.$ fatty alcohol-ethoxylate with an average of 80 ethylene oxide units; BASF), Trit $=$ Triton X-100 (iso-octylphenololigoethoxylate), K30: Emulgator K30/40 (Bayer, sodium alkylsulfonates). [c] US = ultrasound, HP = high-pressure homogenizer (for details see Experimental Section). [d] Mol of ethylene permol of Ni. [e] Average size of latex particles, determined by light scattering. [f] Latex unstable, partial coagulation occured.

(Table 1). Analysis of the isolated polymer by gel-permeation chromatography (GPC) reveals these dispersions to contain only high molecular mass polyethylene with $M_{\mathrm{w}}$ values of up to $4 \times 10^{5} \mathrm{~g} \mathrm{~mol}^{-1}$ and narrow molecular mass distributions. The average latex particle sizes are in the range of 90 to $350 \mathrm{~nm}$, as observed by light scattering measurements. ${ }^{[12]} \mathrm{It}$ should be noted that the polymerization reaction of ethylene reported here differs from typical free-radical polymerization in a preformed mini-emulsion of a liquid monomer. Gaseous ethylene monomer is fed continuously into the reaction mixture after mini-emulsification of the catalyst solution. Thus, polymerization of preformed mini-emulsion droplets of monomer to particles of the same size, as the typical feature of "mini-emulsion polymerization", does not apply.

The polymer latexes obtained are stable for weeks or longer. As a surfactant, various anionic and nonionic compounds were found to be suited, that is, compatible with the catalyst in the mini-emulsion system employed and capable of forming stable latexes (Table 1). As expected, a decrease in the surfactant concentration under otherwise identical conditions resulted in an increase in the average size of the latex particles (entries 2-4). The lower activities observed on employing the high-pressure homogenizer (entries 7-9) relative to ultrasonification are probably related to deactivation of the catalyst precursor, as the former method required more time for mini-emulsification.

The latex particles were visualized by transmission-electron microscopy (TEM; Figure 1). In comparison to smooth, spherical latex particles of amorphous polystyrene, as a well-studied hydrocarbon polymer prepared by free-radical emulsion polymerization, the ruggedness of the particles shown can be rationalized by their high degree of crystallinity ( 39 to $51 \%$ by differential scanning calorimetry (DSC); $T_{\mathrm{m}}=$ $\left.120-130{ }^{\circ} \mathrm{C}\right) \cdot{ }^{[13]}$

\section{Experimental Section}

General: Complex 2a was prepared as described previously. ${ }^{[4 b]}$ The compound was manipulated by standard Schlenk techniques under argon. Deionized water was degassed prior to use. High-temperature GPC was performed in 1,2,4-trichlorobenzene at $140^{\circ} \mathrm{C}$ using a PL-220 instrument equipped with mixed-bed PL columns. The data reported was referenced to polyethylene standards (universal calibration). Dynamic light scattering

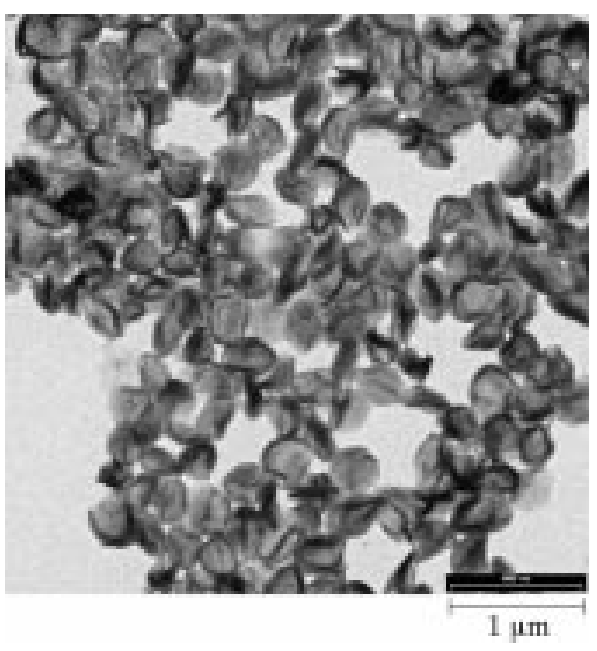

Figure 1. TEM micrograph of latex particles.

measurements on the dispersions were performed on a Malvern particle sizer after dilution. TEM investigations were carried out on a LEO 912 Omega apparatus using an acceleration voltage of $120 \mathrm{kV}$. The DSC data reported were recorded in the second heating cycle at $10 \mathrm{~K} \mathrm{~min}^{-1}$.

Polymerization: The catalyst precursor was dissolved in the given amount of toluene and hexadecane (Table 1). The surfactant and about $100 \mathrm{~mL}$ of water were added with mechanical stirring. Homogenization was performed under an argon atmosphere by means of a high-pressure homogenizer directly connected to the polymerization reactor (modified version of the EmulsiFlex ${ }^{\circledR}-\mathrm{C} 5$ apparatus from Avestin Inc.; 500 - 1000 bar) or by ultrasound (Bandelin HD2200 with KE76 tip; 2 min at $120 \mathrm{~W}$ ). The resulting mini-emulsion was transferred to a mechanically stirred $250-\mathrm{mL}$ pressure reactor equipped with a heating/cooling jacket and a constant ethylene pressure (45 bar) was applied. The reaction temperature was controlled $\left(30^{\circ} \mathrm{C}\right)$ by means of a thermocouple dipping into the reaction mixture. After the specified reaction time the ethylene was vented. The resulting latex was filtered through glass wool. For the determination of yields and for further polymer analysis a specified portion was precipitated by pouring into methanol.

[1] a) Emulsion Polymerization and Emulsion Polymers (Eds.: P. A. Lovell, M. S. El-Aasser), Wiley, Chichester, 1997; b) Wässrige Polymerdispersionen (Ed.: D. Distler), VCH, Weinheim, 1999; c) G. Lagaly, O. Schulz, R. Zimehl, Dispersionen und Emulsionen, Steinkopff, Darmstadt, 1997.

[2] The preparation of latexes on a laboratory scale by other routes has been described, see, for example, a) D. R. Weyenberg, D. E. Findlay, J. Cekada, A. E. Bey, J. Polym. Sci. C 1969, 27, 27-34 (ionic ring- 
opening polymerization of cyclic siloxanes); b) K. Landfester, F. Tiarks, H.-P. Hentze, M. Antonietti, Macromol. Chem. Phys. 2000, 201, $1-5$ (polyaddition).

[3] a) Ziegler Catalysts (Eds.: G. Fink, R. Mülhaupt, H. H. Brintzinger), Springer, Berlin, 1995; b) H. H. Brintzinger, D. Fischer, R. Mülhaupt, B. Rieger, R. Waymouth, Angew. Chem. 1995, 107, 1255-83; Angew. Chem. Int. Ed. Engl. 1995, 34, $1143-1170 ;$ c) G. J. P. Britovsek, V. C. Gibson, D. F. Wass, Angew. Chem. 1999, 111, 448-468; Angew. Chem. Int. Ed. 1999, 38, 428-447; d) W. Kaminsky, M. Arndt, Adv. Polym. Sci. 1997, 127, $143-187$.

[4] a) A. Held, F. M. Bauers, S. Mecking, Chem. Commun. 2000, 301 302; b) F. M. Bauers, S. Mecking, Macromolecules 2001, 34, $1165-$ 1171.

[5] Shortly after our initial report, ${ }^{[4 a]}$ the results of independent investigations by others on $\mathrm{Ni}^{\mathrm{II}}$-catalyzed ethylene polymerization in water were published: A. Tomov, J.-P. Broyer, R. Spitz, Macromol. Symp. 2000, 150, 53-58. See also A. Tomov, R. Spitz, T. Saudemont, X. Drujon (Elf Atochem), WO 00/20464, 2000 [Chem. Abstr. 2000, 132, 279651a].

[6] For suspension-type polymerization of ethylene to high molecular mass amorphous polyethylene, see a) A. Held, S. Mecking, Chem. Eur. J. 2000, 6, 4623-4629, and references therein. For a very slow (one turnover per day) suspension-type Rh-catalyzed ethylene polymerization in water, see b) L. Wang, R. S. Lu, R. Bau, T. C. Flood, J. Am. Chem. Soc. 1993, 115, 6999-7000. Catalytic polymerization of olefinic monomers other than ethylene in water has been described: c) R. E. Rinehart, H. P. Smith, H. S. Witt, H. Romeyn, J. Am. Chem. Soc. 1961, 83, $4864-4865$; d) G. Natta, G. Dall'Asta, L. Porri, Makromol. Chem. 1965, 81, 253-257; e) R. E. Rinehart, J. Polym. Sci. C 1969, 27, 7-25; f) B. M. Novak, R. H. Grubbs, J. Am. Chem. Soc. 1988, 110, $7542-$ 7543; g) D. M. Lynn, B. Mohr, R. H. Grubbs, J. Am. Chem. Soc. 1998, 120, 1627-1628; h) W. Reppe, A. Magin, US-Pat. 2577208, 1951 [Chem. Abstr. 1952, 46, 6143b]; i) Z. Jiang, A. Sen, Macromolecules 1994, 27, 7215 - 7216; j) G. Verspui, G. Papadogianakis, R. A. Sheldon, Chem. Commun. 1998, 401 -402; k) E. Lindner, M. Schmid, J. Wald, J. A. Queisser, M. Geprägs, P. Wegner, C. Nachtigal, J. Organomet. Chem. 2000, 602, $173-187$.

[7] Reviews on late transition metal catalysis for olefin polymerization: a) S. Mecking, Coord. Chem. Rev. 2000, 203, 325-351; b) S. D. Ittel, L. K. Johnson, M. Brookhart, Chem. Rev. 2000, 100, 1169-1204; c) S. Mecking, Angew. Chem. 2001, 113, 550-557; Angew. Chem. Int. Ed. 2001, 40, 534-540; d) ref. [3c].

[8] a) K. A. Ostoja-Starzewski, J. Witte, Angew. Chem. 1987, 99, 76-77; Angew. Chem. Int. Ed. Engl. 1987, 26, 63-64; b) U. Klabunde, S. D. Ittel, J. Mol. Catal. 1987, 41, 123-134.

[9] a) L. K. Johnson, A. M. A. Bennett, S. D. Ittel, L. Wang, A. Parthasarathy, E. Hauptman, R. D. Simpson, J. Feldman, E. B. Coughlin (DuPont), WO 98/30609, 1998 [Chem. Abstr. 1998, 129, 149362j]; b) C. Wang, S. Friedrich, T. R. Younkin, R. T. Li, R. H. Grubbs, D. A. Bansleben, M. W. Day, Organometallics 1998, 17, 3149-3151; c) T. R. Younkin, E. F. Connor, J. I. Henderson, S. K. Friedrich, R. H. Grubbs, D. A. Bansleben, Science 2000, 287, 460-462.

[10] It should be noted that the different mechanisms of chain initiation, growth, and transfer in free-radical versus coordination polymerization can clearly affect the delicate steps involved in particle nucleation and growth. Nonetheless, the general comparison drawn here is reasonable.

[11] For background information on mini-emulsions and the function of the hydrophobe, see a) E. D. Sudol, M. S. El-Aasser in Emulsion Polymerization and Emulsion Polymers (Eds.: P. A. Lovell, M. S. ElAasser), Wiley, Chichester, 1997 pp. 699-722; b) K. Landfester, N. Bechthold, F. Tiarks, M. Antonietti, Macromolecules 1999, 32, 52225228, and references therein.

[12] In regard to the development of particle numbers during polymerization, a comprehensive interpretation of the data is complicated by the necessity of extensively diluting the turbid emulsion for lightscattering analysis. Deviations from the original state may result in analyses of the catalyst mini-emulsion (liquid/liquid dispersion).

[13] Like the polymers obtained in traditional polymerization in organic media with these catalysts, ${ }^{[9]}$ the polyethylenes prepared in water are moderately branched. For the material isolated from dispersions, about 20 branches/1000 carbon atoms (predominantly methyl branch- es) were observed by ${ }^{1} \mathrm{H}$ and ${ }^{13} \mathrm{C}$ NMR spectroscopy. By comparison to linear polyethylene, a moderate decrease in crystallinity results.

[14] Note added upon revision of this manuscript (May 23, 2001): after submission of this manuscript, the preparation of latexes of low molecular mass materials by the polymerization of ethylene employing mini-emulsions of water-stable nickel(II) complexes was reported: R. Soula, C. Novat, A. Tomov, R. Spitz, J. Claverie, X. Drujon, J. Malinge, T. Saudemont, Macromolecules 2001, 34, 2022-2026. 